\title{
STUDY OF THE ANTICANCER POTENTIAL OF CELERY SEED OIL AGAINST CHEMICALLY INDUCED HEPATOCELLULAR CARCINOMA IN RATS: A MECHANISTIC APPROACH.
}

\section{BY}

\author{
Omaima A.M. Ahmedy $^{1 *}$, Mostafa E. El-sayed ${ }^{1}$, Afaf A. Shoka ${ }^{1}$, Hekma A. Abd El- \\ Latif $^{1}$, Ashraf K. Bahgat ${ }^{1}$ and Azza Hassan ${ }^{2}$
}

\section{FROM}

${ }^{1}$ Department of Pharmacology and Toxicology, Faculty of Pharmacy, Cairo University, Cairo, Egypt

${ }^{2}$ Department of Pathology, Faculty of Veterinary Medicine, Cairo University, Cairo, Egypt.

\begin{abstract}
Hepatocellular carcinoma (HCC), the major primary malignant tumour of the liver, represents a complex and fatal malignancy driven primarily by oxidative stress and inflammation. Celery seed oil (CSO) is a rich source of phytochemicals endowed with potent antioxidant and anti-inflammatory properties. In this study, we examined the molecular mechanisms by which CSO inhibited diethylnitrosamine (DENA)induced hepatocellular carcinoma in rats by analysing the expression patterns of proliferating cell nuclear antigen (PCNA), nuclear factor-kappaB (NF-kB), cyclooxygenase-2 (COX-2), and caspase-3 immunohistochemically. In addition, serum TNF- $\alpha$ level and liver nitric oxide content were investigated. Rats were administered CSO (300 mg/kg, p.o.) four weeks after DENA-induced HCC. There was a significant elevation in serum TNF- $\alpha$ level and liver nitric oxide content, upregulation of PCNA, NF-kB and COX-2 in DENA-exposed rats. Administration of CSO decreased the expression of PCNA and increased the expression of caspase-3, indicating antiproliferative and apoptotic effects, respectively. Moreover, CSO markedly suppressed all aforementioned elevated inflammatory parameters. Our study provides evidence that CSO exerts its anticancer effect through antiproliferative, proapoptotic and anti-inflammatory mechanisms.
\end{abstract}

Key words: Celery, hepatocellular carcinoma, PCNA, COX-2, NF-kB, apoptosis.

\section{Introduction}

Hepatocellular carcinoma (HCC) is a malignant neoplasm of hepatocytes that is considered as the most common primary cancer of liver, one of the world's deadliest cancers and now the second prominent cause of cancer-related mortalities, resulting in 782,000 cases estimated to have occurred in 2012 (El-Serag 2011; Wallace et al. 2015). HCC is a distinctive type of cancer that typically arises in the setting of chronic liver disease at a rate dependent upon the complex interaction between the host, disease and environmental factors (Wallace et al. 2015).

Cancer arises as a result of genetic changes leading to insensitivity to antigrowth signals, evasion of apoptosis, unlimited replicative potential, sustained angiogenesis, and tissue invasion and metastasis. Changes in the expression of molecules that regulate cell cycle and cell proliferation pathways are disturbed in malignant cells resulting in 
loss of control of cell proliferation. PCNA functions as auxiliary protein for DNA polymerase $\delta$, which is required for DNA synthesis and cell cycle progression. Furthermore, the rate of PCNA synthesis is linked with the proliferative rate of cells (Oyama et al. 2002; Stoimenov and Helleday 2009; Strzalka and Ziemienowicz 2011).

Dysregulation of apoptosis increases susceptibility to enhanced cell proliferation and cell survival (Plati et al. 2011). Moreover, apoptosis evasion is recognized as a prerequisite for cancer cell to acquire permissive environment for angiogenesis, invasion and metastasis. (Diaz-Cano 2008; Hanahan and Weinberg 2011; Plati et al. 2011).

Increasing evidences from preclinical and clinical studies support that dysregulated inflammatory response plays a pivotal role in a multitude of chronic ailments including cancer (Ben-Neriah and Karin 2011). The molecular mechanism(s) by which chronic inflammation drives cancer initiation and promotion include increased production of pro-inflammatory mediators, such as cytokines, chemokines, reactive oxygen intermediates, increased expression of oncogenes, COX-2 (cyclo-oxygenase-2), 5-LOX (5-lipoxygenase), and pro-inflammatory transcription factors, such as NF-kB (nuclear factor-kappaB), that mediate tumour cell proliferation, transformation, metastasis, survival, invasion and angiogenesis (Luqman and Pezzuto 2010; Tan et al. 2011). Moreover, transcription factor nuclear NF-kB regulates the expression of a wide variety of genes involved in cellular events such as inflammation, immune response, proliferation, apoptosis and cancer invasion (Chaturvedi et al. 2011).

Therefore, medicinal plants and dietary phytochemicals that are capable of targeting multiple molecules in disease signalling pathways are considered as promising candidate for chemoprevention and chemotherapeutic protocols.

Celery (Apium graveolens) seeds locally known as "Karfas" have been widely used in traditional medicine for the treatment of liver and spleen diseases, jaundice rheumatism, gout, and other inflammatory disorders (Al-Asmari et al. 2014). The phytochemical screening of celery showed the presence of various chemical constituents such as flavonoids, phenolic acids, tannins, volatile oils, alkaloids, sterols and/or triterpenes (Al-Howiriny et al. 2010). Numerous studies reported that celery seeds possesses anti-inflammatory, antioxidant and cytotoxic properties (Ren and Lien 1997; Sultana et al. 2005; Powanda et al. 2015).

The anticancer effect of CSO against $\mathrm{HCC}$ in rats has been investigated in vivo (Sultana et al. 2005). However, the possible molecular and cellular mechanism of CSO against $\mathrm{HCC}$ is yet to be elucidated. In this study, we investigated the modulatory effects of CSO on the expression of various cellular markers, such as PCNA, caspase-3, COX-2 and the pro-inflammatory transcription factor NF-kB in DENA induced hepatocellular carcinoma in rats.

\section{Materials and methods}

\section{Chemicals}

Diethylnitrosamine (DENA) was purchased from Sigma Aldrich (St. Louis, MO, USA) and celery seed oil was obtained from a commercial source (Hashem Brothers for essential oils \& aromatic products, Benisuef, Egypt). All other chemicals used were of the highest purity and analytical grade. 


\section{Animals and diet}

Male Wistar albino rats weighing 90-120 g were used in the present study. They were obtained from the breeding colony maintained at the animal house of the Nile Pharmaceuticals Company (Cairo, Egypt). They were allowed an acclimatization period for at least one week prior to the experiment. Animals were kept under controlled environmental conditions; room temperature $\left(24-27^{\circ} \mathrm{C}\right)$, constant humidity $(60 \pm 10 \%)$, with alternating $12 \mathrm{~h}$ light and dark cycles. Standard pellet diet and water were allowed ad libitum. All animals' procedures were performed in accordance with the ethical guidlines and policies approved by the Ethics Committee of Faculty of Pharmacy, Cairo University and complies with the Guide for the Care and Use of Laboratory Animals published by the US National Institutes of Health (NIH Publication No. 85-23, revised 1996).

\section{Experimental design}

After a period of adaptation, all animals except the normal group were intraperitoneally injected with DENA $(20 \mathrm{mg} / \mathrm{kg}$ ) five times weekly for 6 consecutive weeks to induce HCC (Ahmed et al. 2013). Animals were randomly assigned into a normal control group and diethylnitrosamine-induced HCC group (DENA). After tumour induction (6 weeks), the DENA group was distributed into 2 groups, a control HCC group and CSO treated group, each composed of 6-8 rats. CSO treatment was carried out by the daily oral administration of CSO $(300 \mathrm{mg} / \mathrm{kg})$ for four consecutive weeks from the $7^{\text {th }}$ week until the end of the $10^{\text {th }}$ week (Baananou et al. 2013) .

\section{Blood sampling and serum preparation}

At the end of the treatment period, blood samples were taken from retro-orbital sinus of rats under ether anaesthesia. Blood samples were allowed to clot at room temperature then serum was separated by centrifugation of blood at $3000 \mathrm{rpm}$ for 15 minutes using a centrifuge (Hettich universal 32A, Germany). Serum samples were designated for the estimation of TNF- $\alpha$ and stored at $-80^{\circ} \mathrm{C}$ until analysis is performed.

\section{Tissue sampling}

Animals were then sacrificed by cervical dislocation, livers were carefully and rapidly excised.

Samples of the liver, from different lobes were homogenized in ice-cold saline, using a homogenizer (Heidolph Diax 900, Germany), to prepare 20\% homogenate. The prepared homogenate was stored at $-80^{\circ} \mathrm{C}$ until assayed later for estimation of the liver nitric oxide content. Samples from the remaining parts were fixed with $10 \%$ formaldehyde for the immunohistochemical examination. The dead bodies were frozen till incineration.

\section{Estimation of Biochemical Parameters}

Estimation of liver nitric oxide content

Liver homogenate was used for determination of nitric oxide content according to the method described by (Miranda et al. 2001). 


\section{Estimation of serum TNF- $\alpha$ level}

Tumour necrosis factor alpha (TNF- $\alpha$ ) was assessed using enzyme-linked immunosorbent assay (ELISA kits) according to the manufacturer specifications (R\&D Systems, Inc., Minneapolis, USA).

\section{Immunohistochemical analysis of liver tissue}

Five $\mu \mathrm{m}$ thick sections were prepared from formalin fixed livers of different animal groups and immunohistochemistry was performed. Sections were placed on positively charged slides, deparaffinised, rehydrated and endogenous peroxidase activity was blocked with $\mathrm{H}_{2} \mathrm{O}_{2}$ in methanol. Sections were pre-treated in citrate buffer ( $\mathrm{pH}$ 6.0) in a microwave. The sections were incubated with the mouse monoclonal antibody (PCNA) and various primary rabbit polyclonal antibodies NF- $\kappa \mathrm{B}, \mathrm{COX}-2$ and caspase- 3 (Thermo Scientific, USA). The sections were incubated with biotinylated goat antipolyvalent, then with streptavidin peroxidase and finally with diaminobenzedine plus chromogen. The slides were visualized under light microscope and the extent of cell immunopositivity was assessed. The number of immunopositive cells was counted in 10 separate microscopic fields/animal, the results were expressed as percentage of total cell per field and the mean value for each slide was obtained, then the mean \pm S.E.M. was calculated for each group $(n=5)$.

\section{Statistical analysis}

Data are expressed as means \pm standard error (S.E.M). Comparisons between means were carried out using one way analysis of variance (ANOVA) test followed by Tukey-Kramer multiple comparison's test. For all statistical tests, the level of significance was fixed at $\mathrm{p}<0.05$. GraphPad Prism ${ }^{\circledR}$ software package, version 6 (GraphPad Software, Inc., USA) was used to carry out all statistical tests.

\section{Results}

\section{Effect of celery seed oil on PCNA expression in DENA-induced HCC in rats.}

As shown in [Figure (1)A-D], the immunohistochemical staining depicts the differential expression of levels of the proliferative marker, PCNA, in liver sections obtained from the various experimental rats groups. Near to complete absence of PCNA-positive cells was observed in normal control group [Figure (1)A]. An increase in hepatic PCNA expression was contrastingly observed in rats treated with DENA alone [Figure (1)B]. CSO (300 mg/kg) after HCC induction resulted in a significant decrease in PCNA expression relative to the untreated HCC rats [Figure (1)C].

[Figure (1)D] represent the quantitative analysis in the frequency of PCNA expressing hepatocytes in the different experimental group. In comparison to the DENA rats, CSO treatment is shown to significantly reduce the number of PCNA-positive cells by $41.64 \%$. 

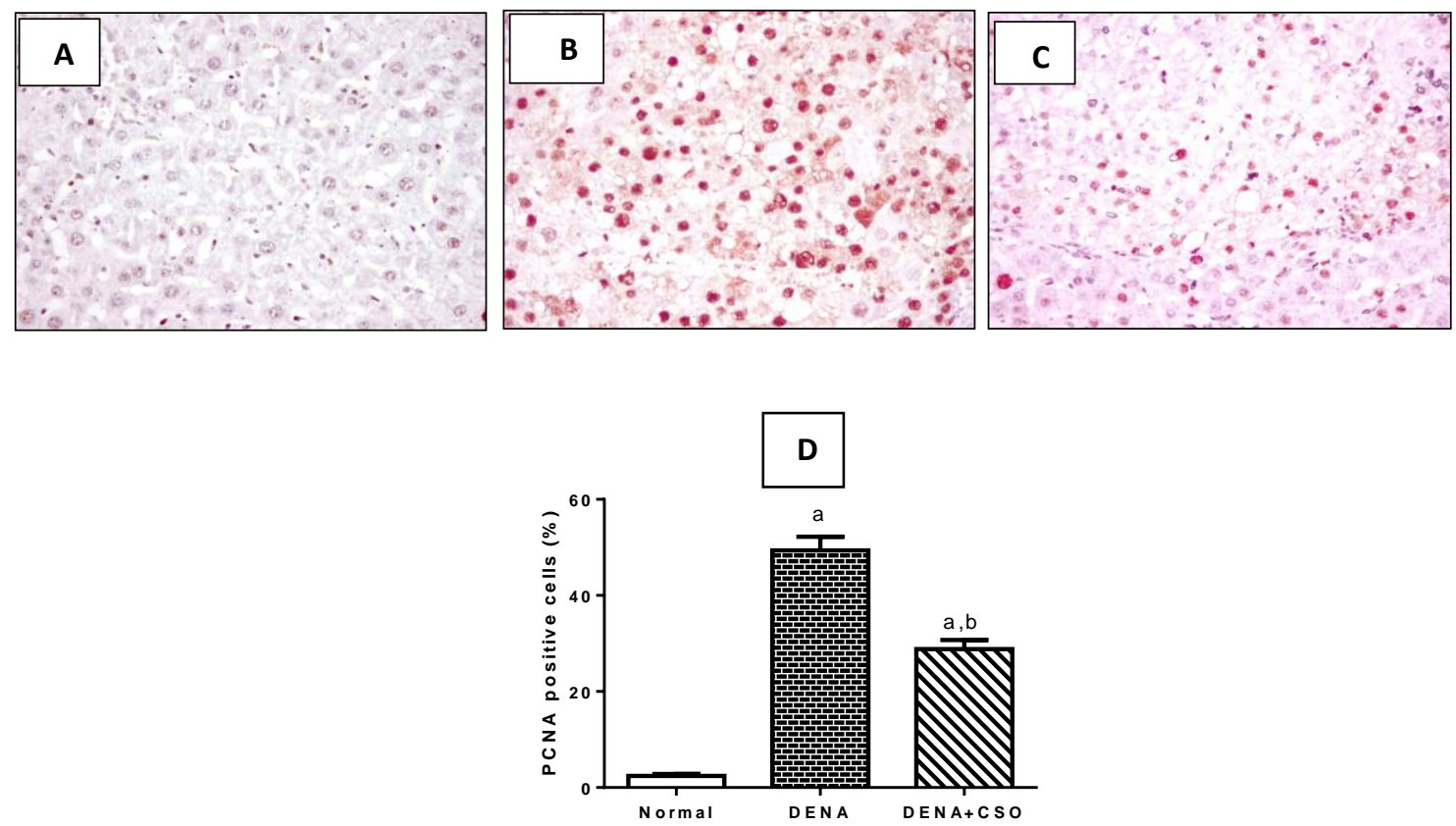

Figure (1): Effect of celery seed oil $(300 \mathrm{mg} / \mathrm{kg})$ on PCNA expression in DENAinduced $\mathrm{HCC}$ in rats.

Representative photomicrograph of immunohistochemical staining of PCNA in rat liver from: $(A, 400 \times)$ normal control group showing no expression of PCNA; (B, 400x) DENA-induced hepatocellular carcinoma showing a significant increase in PCNA immunoreactivity in the nucleus of hepatocytes; $(C, 400 \times)$ DENA + CSO group showing a significant reduction in PCNA immunostaining. Brown colour indicates PCNA positivity; (D) percentage expression of PCNA.

DENA = diethylnitrosamine, $\mathrm{CSO}=$ celery seed oil and $\mathrm{HCC}=$ hepatocellular carcinoma .

Values are expressed as means \pm S.E.M. $(n=5)$.

The significance of the difference between means was tested by ANOVA followed by Tukey Kramer multiple comparisons test.

${ }^{a}$ Significantly different from control, ${ }^{b}$ Significantly different from DENA at $p<0.05$.

Effect of celery seed oil on caspase-3 expression in DENA-induced HCC in rats.

The changes in caspase- 3 expression are illustrated in [Figure (2)A-D], caspase3 positive cells was not detected in normal control rats [Figure (2)A]. However, DENA exposed rats showed a rise in caspase-3 expression relative to the normal control [Figure (2)B. CSO (300 mg/kg) administration displayed profound apoptotic activity and resulted in a marked upregulation of caspase-3 expression as compared to DENAinduced HCC rats group [Figure (2)C]. [Figure (2)D] represent the quantitative analysis of caspase-3 expressing hepatocytes in the different experimental groups. CSO treatment is shown to significantly augment (1.2 folds) the number of caspase-positive cells relative to the untreated DENA-induced HCC rats. 

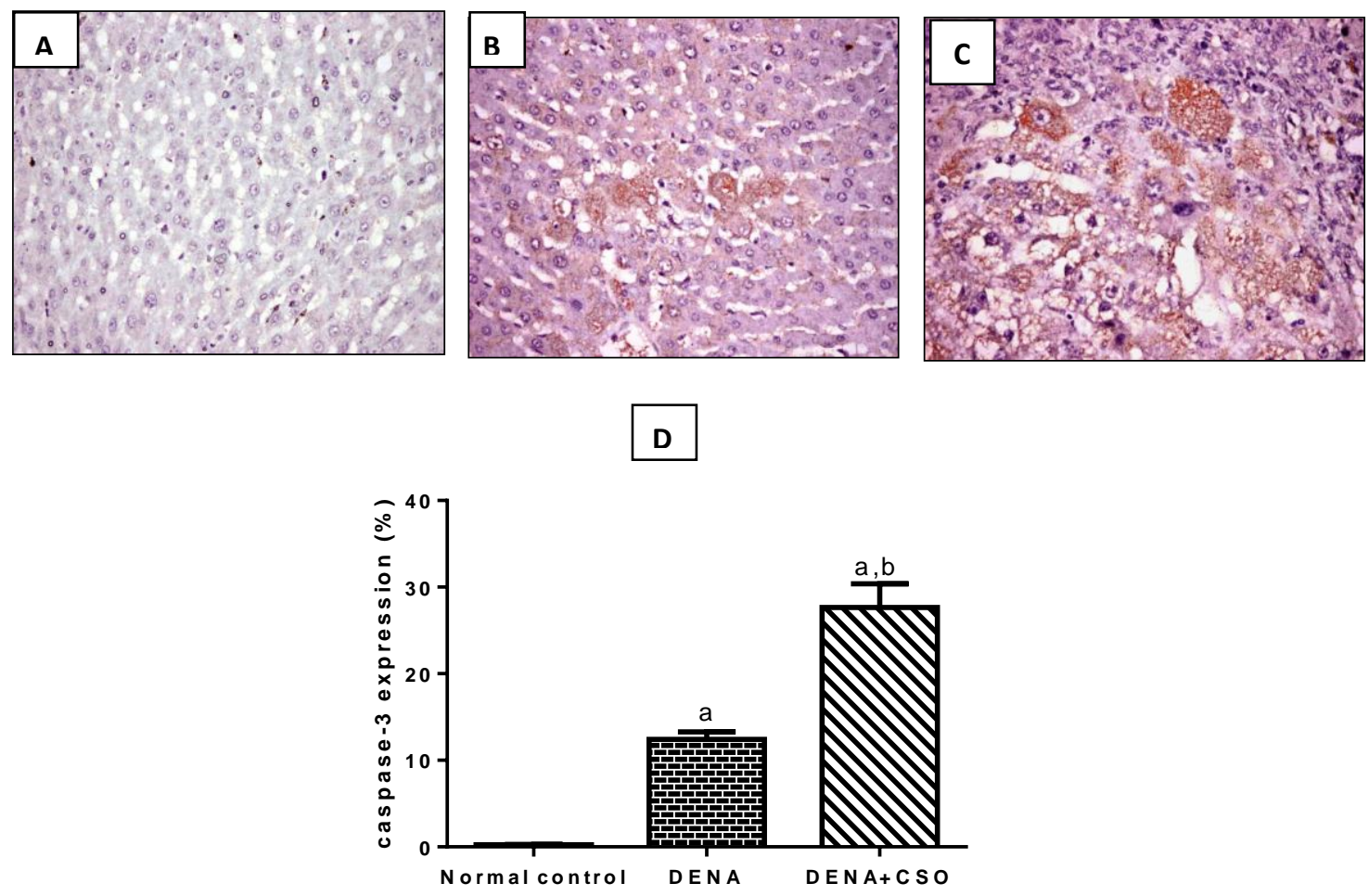

Figure (2): Effect of celery seed oil (300 $\mathrm{mg} / \mathrm{kg})$ on caspase-3 expression in DENAinduced $\mathrm{HCC}$ in rats.

Representative photomicrograph of immunohistochemical staining of caspase-3 in rat liver from: $(A, 400 \times)$ normal control group showing no expression of caspase-3; $(B, 400 \times)$ DENA-induced hepatocellular carcinoman showing a significant increase in caspase-3 immunoreactivity in the cytoplasm of hepatocytes; $(C, 400 \times)$ DENA + CSO group showing an additional significant increase in caspase-3 immunostaining. Brown colour indicates caspase-3 positivity; (D) percentage expression of caspase-3.

DENA = diethylnitrosamine, $\mathrm{CSO}=$ celery seed oil, $\mathrm{HCC}=$ hepatocellular carcinoma and $\mathrm{ND}=$ non detectable

Values are expressed as means \pm S.E.M. $(n=5)$.

The significance of the difference between means was tested by ANOVA followed by Tukey Kramer multiple comparisons test.

${ }^{a}$ Significantly different from control, ${ }^{b}$ Significantly different from DENA at $p<0.05$.

Effect of celery seed oil on serum TNF- $\alpha$ and liver nitric oxide in DENA-induced $\mathrm{HCC}$ in rats.

As shown in Table (1), induction of HCC by DENA significantly increased the serum TNF- $\alpha$ to $(51.83 \mathrm{pg} / \mathrm{ml})$ relative to the normal control $(23.93 \mathrm{pg} / \mathrm{ml})$. Additionally, liver nitric oxide content was markedly augmented to $(201.26 \mu \mathrm{mol} / \mathrm{g}$ 
liver) as compared to the normal control (79.97 $\mu \mathrm{mol} / \mathrm{g}$ liver). CSO (300 $\mathrm{mg} / \mathrm{kg}$ ) administration after HCC induction resulted in a remarkable decrease in the upsurge of TNF- $\alpha$ serum level $(25.97 \%)$ and liver nitric oxide content $(47.19 \%)$ relative to the untreated DENA -induced HCC rats.

Table (1): Effect of celery seed oil $(300 \mathrm{mg} / \mathrm{kg})$ on serum TNF- $\alpha$ level and liver nitric oxide content in DENA-induced HCC in rats.

\begin{tabular}{|c|c|c|}
\hline Parameters & $\begin{array}{r}\text { Serum TNF-a } \\
(\mathrm{pg} / \mathrm{ml})\end{array}$ & $\begin{array}{r}\text { Liver nitric oxide } \\
(\mu \mathrm{mol} / \mathrm{g} \text { liver })\end{array}$ \\
\hline Normal control & $23.93 \pm 1.49$ & $79.97 \pm 8.24$ \\
\hline $\begin{array}{c}\text { (DENA) } \\
(20 \text { mg/kg, i.p. })\end{array}$ & $5^{21.83}{ }^{\mathrm{a}} \pm 2.35$ & $201.26^{\mathrm{a}} \pm 19.53$ \\
\hline $\begin{array}{c}\text { DENA + CSO } \\
(300 \mathrm{mg} / \mathrm{kg}, \text { p.o. })\end{array}$ & $38.37^{\mathrm{a}, \mathrm{b}} \pm 4.43$ & $106.28^{\mathrm{b}} \pm 10.68$ \\
\hline
\end{tabular}

DENA $=$ diethylnitrosamine, $\mathrm{CSO}=$ celery seed oil, $\mathrm{TNF}-\alpha=$ tumour necrosis factor alpha.

Values are expressed as means \pm S.E.M. $(n=6-8)$.

The significance of the difference between means was tested by ANOVA followed by Tukey- Kramer multiple comparisons test.

* Significantly different from control, @ Significantly different from DENA at $p<0.05$.

Effect of celery seed oil on NF- $\mathrm{KB}$ expression in DENA-induced HCC in rats.

[Figure (3)A-D] depicts the immunohistochemical staining of the differential expression of NF- $\kappa B$, in liver sections obtained from the different rat groups. Absence of NF- $\mathrm{KB}$ was observed in normal control group [Figure (3)A]. However, a marked increase in hepatic NF- $\kappa \mathrm{B}$ expression was observed in rats administered DENA alone relative to the normal control group [Figure (3)B]. Treatment with CSO (300 mg/kg) after $\mathrm{HCC}$ induction caused a significant decrease in NF- $\kappa \mathrm{B}$ expression as compared to the HCC untreated rats [Figure (3)C]. [Figure (1)D] shows the quantitative analysis in the hepatic NF- $\kappa \mathrm{B}$ expression in the different experimental group. Relative the DENA induced $\mathrm{HCC}$ rats, CSO treatment markedly reduced the number of NF- $\kappa \mathrm{B}$-positive cells by $48.51 \%$. 

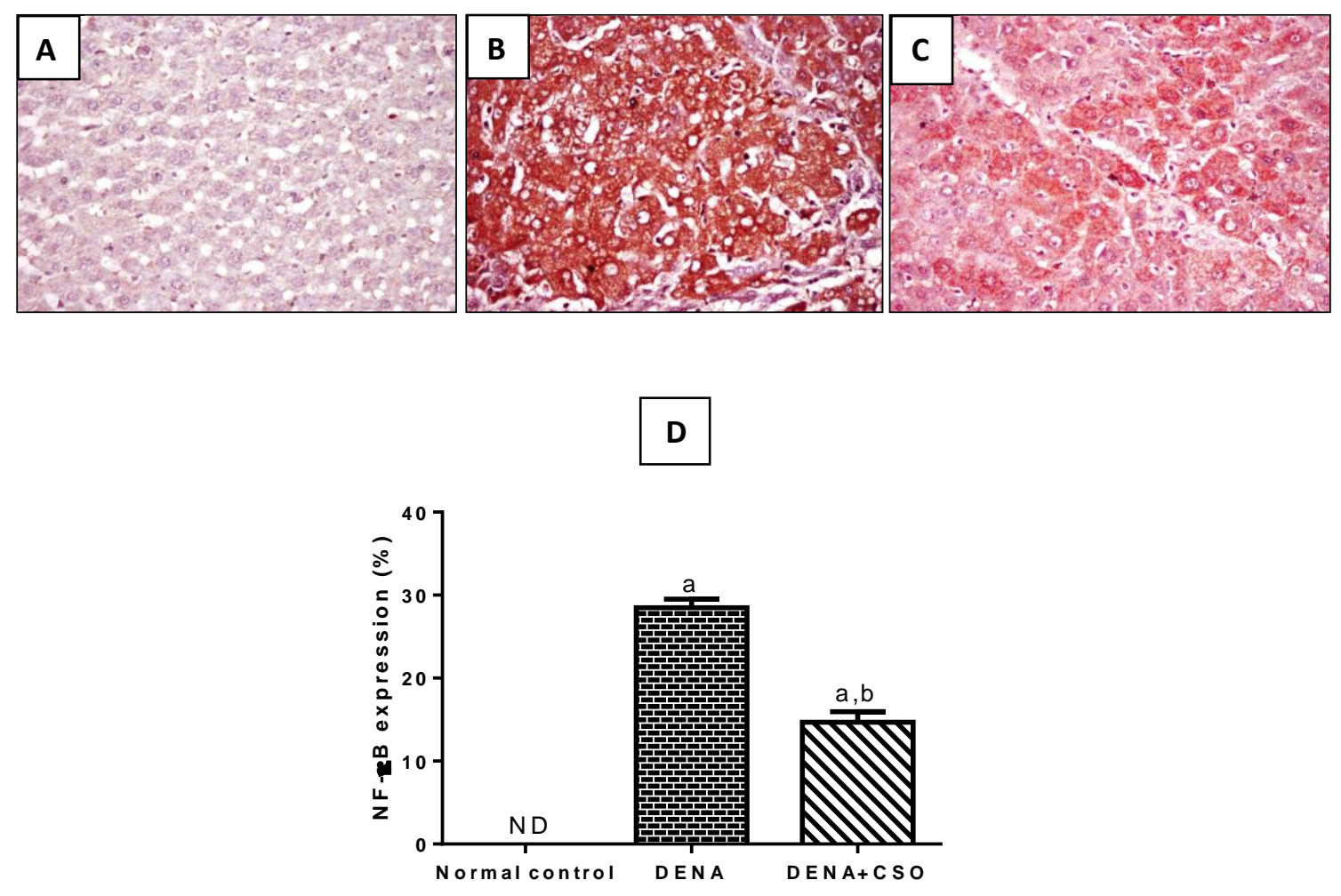

Figure (3): Effect of celery seed oil $(300 \mathrm{mg} / \mathrm{kg})$ on NF-kB expression in DENAinduced $\mathrm{HCC}$ in rats.

Representative photomicrograph of immunohistochemical staining of NF- $\kappa \mathrm{B}$ in rat liver from: $(A, 400 \times)$ normal control group showing no expression of NF- $\mathrm{KB}$; (B, 400x) DENA-induced hepatocellular carcinoma showing a significant increase in NF- $\kappa B$ immunoreactivity in the cytoplasm of hepatocytes; $(C, 400 \times)$ DENA + CSO group showing a significant reduction in NF-KB immunostaining. Brown colour

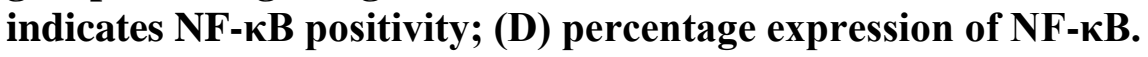

DENA $=$ diethylnitrosamine, $\mathrm{CSO}=$ celery seed oil, $\mathrm{HCC}=$ hepatocellular carcinoma and $\mathrm{ND}=$ non detectable

Values are expressed as means \pm S.E.M. $(n=5)$.

The significance of the difference between means was tested by ANOVA followed by Tukey Kramer multiple comparisons test.

${ }^{a}$ Significantly different from control, ${ }^{b}$ Significantly different from DENA at $\mathrm{p}<0.05$. 
Effect of celery seed oil on COX-2 expression in DENA-induced HCC in rats.

As shown in [Figure (4)A-D], the immunohistochemical staining shows the differential expression levels of COX-2 in liver sections obtained from the various experimental rat groups. An almost complete absence of COX-2-positive cells was observed in normal control group [Figure (4)A]. An increase in hepatic COX-2 expression was contrastingly observed in rats treated with DENA alone [Figure (4)B]. Administration of CSO $(300 \mathrm{mg} / \mathrm{kg})$ after $\mathrm{HCC}$ induction resulted in a significant decrease in COX-2 expression [Figure (4)C].

[Figure (4)D] represent the quantitative analysis in the frequency of COX-2 expressing hepatocytes in the different experimental group. As compared to the DENA-induced HCC rats, CSO treatment is shown to significantly reduce the number of COX-2positive cells to $49.79 \%$.
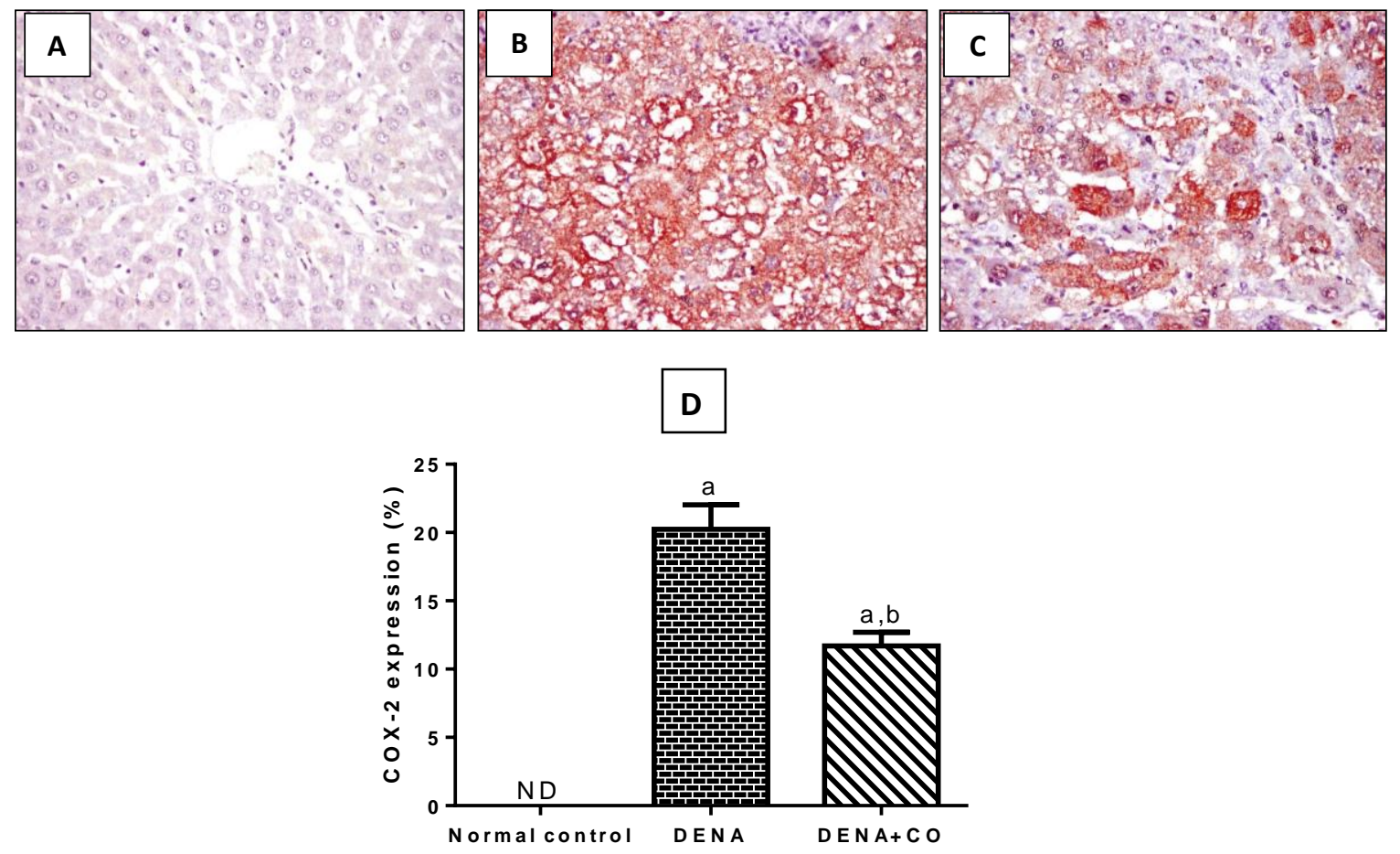

Figure (4): Effect of celery seed oil $(300 \mathrm{mg} / \mathrm{kg})$ on COX-2 expression in DENAinduced $\mathrm{HCC}$ in rats.

Representative photomicrograph of immunohistochemical staining of COX-2 in rat liver from: $(\mathrm{A}, 400 \times)$ normal control group showing no expression of COX-2; $(B, 400 \times)$ DENA-induced hepatocellular carcinoma showing a significant increase in COX-2 immunoreactivity in the cytoplasm of hepatocytes; $(C, 400 \times)$ DENA + CSO group showing a significant reduction in COX-2 immunostaining. Brown colour indicates COX-2 positivity; (D) percentage expression of COX-2.

DENA = diethylnitrosamine, $\mathrm{CSO}=$ celery seed oil, $\mathrm{HCC}=$ hepatocellular carcinoma and $\mathrm{ND}=$ non detectable

Values are expressed as means \pm S.E.M. $(n=5)$. 
The significance of the difference between means was tested by ANOVA followed by Tukey Kramer multiple comparisons test.

${ }^{a}$ Significantly different from control, ${ }^{\mathrm{b}}$ Significantly different from DENA at $\mathrm{p}<0.05$.

\section{Discussion}

DENA usually causes genomic damage in exposed cells. As a consequence, the damaged cells may be triggered to proliferate with genomic damage, leading to the formation of cancerous cells that showed apoptosis evasion, increased cell proliferation, angiogenesis, invasion and metastasis (Hanahan and Weinberg 2011). In the present study, we have demonstrated that CSO was capable of modulating important proteins involved in cell proliferation, inflammation and apoptosis resulting in suppression of hepatocarcinogenesis induced by administration of DENA.

Abnormal cell proliferation is the main feature of carcinogenesis, making inhibition of the excessive proliferation of tumour cells is an effective therapeutic approach. PCNA, a marker of cell proliferation, is associated with DNA synthesis phase of the cell cycle (Oyama et al. 2002). The positive expression of PCNA is considered a common index for hepatocyte proliferation at late G1- and early S-phase. Moreover, PCNA represents an important cellular marker for assessing the proliferation in hepatocellular carcinoma (Qin and Tang 2002). In our study, the expression of PCNA was examined immunohistochemically in livers from the different animal groups. DENA-treated animals resulted in a drastic increase in PCNA expression, indicating accelerated cell proliferation in rat liver tumour. In agreement with our findings, it has been reported that DENA enhances hepatocytes proliferation and augments PCNA expression in rats (Song et al. 2013). Significant decrease in PCNA-positive hepatocytes due to CSO treatment clearly indicates a decrease in hepatocyte proliferation, possibly through inhibition of DNA synthesis in experimentally induced HCC in rats. Our data showing diminished hepatic PCNA expression and enhanced cell proliferation are concordant with a previous study showing antiproliferative effect of celery seed extract in vivo cancer model (Sultana et al. 2005).

Apoptosis or programmed cell death is involved in tissue homeostasis through targeted elimination of cells without disrupting the normal physiological function of the tissue. Dysregulation of apoptosis disturbing the balance between cell proliferation and cell death are involved in the development and progression of hepatic cancer (Fabregat 2009; Schattenberg et al. 2011). Apoptosis detection in tumour has emerged as valuable diagnostic tool and induction of tumour cell death by apoptosis has been recognized as one of the essential objectives of liver cancer therapy (Karamitopoulou et al. 2007). Apoptosis enhancement in tumour-target tissues has been identified as an innovative mechanism of potential chemopreventive and chemotherapeutic drug.

In the present study, caspase-3 was immuhistochemically detected to identify cells undergoing apoptosis. Our results show a low order of hepatic caspase-3 expression in DENA-exposed rat livers indicating apoptosis evasion (Bhatia et al. 2013). CSO treatment showed a manifest increase in the caspase-3 expression, which provides considerable evidence of induction of cell death by apoptosis.

TNF- $\alpha$, a potent pleiotropic proinflammatory cytokines, affects the growth, differentiation and survival of all cells (Anderson et al. 2004). Existing evidence 
indicates that high levels of TNF- $\alpha$ can favour cell survival and tumour progression (Mocellin et al. 2005).

In the present study, there was a marked increase in serum TNF- $\alpha$ in DENAinduced tumour group animals. This finding is consistent with a previous study that DENA-induced HCC in rats led to an increase in serum TNF- $\alpha$ level (Song et al. 2013). The diminished level of TNF- $\alpha$ in rats with DENA-induced HCC by the administration of CSO may be related to its anti-inflammatory and anti-tumour activities (Atta and Alkofahi 1998; Sultana et al. 2005).

Increased nitric oxide production in liver tissue was reported to be involved in the pathogenesis of HCC (Bishayee et al. 2010; Lee and Lim 2012). This can be explained by the ability of TNF- $\alpha$ to up-regulate the iNOS enzyme ( Morris, Jr. and Billiar 1994; Du et al. 2009). Moreover, several studies on human cancer and animal tumour model have documented that increased tumour expression of COX-2, was associated with more aggressive lesions that sustain inflammation, tumour growth and metastasis ( Noriyuki et al. 2007; Liao et al. 2010).

In agreement with previous studies, DENA caused a significant increase in the liver nitric oxide content (Bishayee et al. 2010; Lee and Lim 2012). CSO administration after HCC induction markedly diminished the elevated liver NO content, an effect that might be related to its anti-inflammatory activities (Momin and Nair 2002; Sultana et al. 2005)

Numerous studies reported that increased expression of NF-kB with subsequent inflammatory reactions were responsible for hepatic injury in HCC (Ueno et al. 2005; Yokoo et al. 2011). It has been reported that activation of NF-kB can convert inflammatory stimuli into tumour growth signals that are mediated by cytokines, chemokines, prostaglandins, nitric oxide and leukotrienes, which contribute to tumour promotion by altering normal cellular signalling cascades (Morrison 2012). Additionally, elevated TNF- $\alpha$ is known to be an important step for activation of the NFkB signalling pathway (Du et al. 2009; Shukla et al. 2011). In the current investigation, $\mathrm{HCC}$ induction resulted in a remarkable increased expression of NF-kB. In agreement with our findings, DENA administration caused upregulation of NF-kB that binds to DNA and results in transcription of genes that contribute to tumourigenesis, such as cell proliferation, inflammatory, anti-apoptotic and positive regulators of cell proliferation (Sivaramakrishnan and Niranjali 2009; Khan et al. 2011). Treatment with CSO significantly suppressed the overexpression of NF-kB, an effect that may be related to its anti-inflammatory properties(Atta and Alkofahi 1998; Momin and Nair 2002)

Moreover, result from a different study have shown that NF-kB induces the activation of COX-2, a primary mediator of the inflammatory cascade, which ensues directly after hepatic cancer mediated liver injury (Sivaramakrishnan and Niranjali 2009; Bishayee et al. 2013). Studies have also shown that selective COX-2 inhibition exerted a chemopreventive effect in human colorectal carcinoma(Bottone, Jr. et al. 2004). In agreement with earlier studies, DENA-induced HCC resulted in a marked overexpression of COX-2 immunohistochemically (Bishayee et al. 2013; Bayomi et al. 2015). CSO treated HCC rat liver manifested a significant downregulation of COX-2 expression related to the untreated DENA-induced HCC animals, this ameliorative effect may be attributed to the cyclooxygenase inhibitory effect of celery seeds (Momin and Nair 2002). 


\section{Conclusion}

Our study demonstrates that the inhibition of cell proliferation, upregulation of apoptosis and down regulation of inflammatory markers may be, at least in part, the underlying mechanisms related to the liver tumour inhibition by CSO. The present study allows us to conclude that CSO being a dietary supplement, may be a promising candidate against hepatocellularcarcinoma.

Reference

Ahmed, H. H., Shousha, W. G., El-Mezayen, H. A., Ismaiel, N. N., and Mahmoud, N. S. (2013). In vivo antitumor potential of carvacrol against hepatocellular carcinoma in rat model. World Journal Of Pharmacy And Pharmaceutical Sciences. 2(5), 2367-2396.

Al-Asmari, A. K., Al-Elaiwi, A. M., Athar, M. T., Tariq, M., Al, E. A., and AlAsmary, S. M. (2014). A review of hepatoprotective plants used in saudi traditional medicine. Evid. Based. Complement Alternat. Med. 2014, 890842.

Al-Howiriny, T., Alsheikh, A., Alqasoumi, S., Al-Yahya, M., ElTahir, K., and Rafatullah, S. (2010). Gastric antiulcer, antisecretory and cytoprotective properties of celery (Apium graveolens) in rats. Pharm. Biol. 48(7), 786-793.

Anderson, G. M., Nakada, M. T., and DeWitte, M. (2004). Tumor necrosis factoralpha in the pathogenesis and treatment of cancer. Curr. Opin. Pharmacol. 4(4), 314-320.

Atta, A. H., and Alkofahi, A. (1998). Anti-nociceptive and anti-inflammatory effects of some Jordanian medicinal plant extracts. J Ethnopharmacol. 60(2), 117124.

Baananou, S., Bouftira, I., Mahmoud, A., Boukef, K., Marongiu, B., and Boughattas, N. A. (2013). Antiulcerogenic and antibacterial activities of Apium graveolens essential oil and extract. Nat. Prod. Res. 27(12), 1075-1083.

Bayomi, E. A., Barakat, A. B., El-Bassuoni, M. A., Talaat, R. M., El-Deftar, M. M., Abdel Wahab, S. A., and Metwally, A. M. (2015). Cyclooxygenase-2 expression is associated with elevated aspartate aminotransferase level in hepatocellular carcinoma. J Cancer Res. Ther. 11(4), 786-792.

Ben-Neriah, Y., and Karin, M. (2011). Inflammation meets cancer, with NF-kappaB as the matchmaker. Nat. Immunol. 12(8), 715-723.

Bhatia, D., Thoppil, R. J., Mandal, A., Samtani, K. A., Darvesh, A. S., and Bishayee, A. (2013). Pomegranate Bioactive Constituents Suppress Cell Proliferation and Induce Apoptosis in an Experimental Model of Hepatocellular Carcinoma: Role of Wnt/ beta -Catenin Signaling Pathway. Evid. Based. Complement Alternat. Med. 2013, 371813.

Bishayee, A., Barnes, K. F., Bhatia, D., Darvesh, A. S., and Carroll, R. T. (2010). Resveratrol suppresses oxidative stress and inflammatory response in diethylnitrosamine-initiated rat hepatocarcinogenesis. Cancer Prev. Res. (Phila) 3(6), 753-763. 
Bishayee, A., Thoppil, R. J., Darvesh, A. S., Ohanyan, V., Meszaros, J. G., and Bhatia, D. (2013). Pomegranate phytoconstituents blunt the inflammatory cascade in a chemically induced rodent model of hepatocellular carcinogenesis. J Nutr. Biochem. 24(1), 178-187.

Bottone, F. G., Jr., Martinez, J. M., Alston-Mills, B., and Eling, T. E. (2004). Gene modulation by Cox-1 and Cox-2 specific inhibitors in human colorectal carcinoma cancer cells. Carcinogenesis 25(3), 349-357.

Chaturvedi, M. M., Sung, B., Yadav, V. R., Kannappan, R., and Aggarwal, B. B. (2011). NF-kappaB addiction and its role in cancer: 'one size does not fit all'. Oncogene 30(14), 1615-1630.

Diaz-Cano, S. J. (2008). General morphological and biological features of neoplasms: integration of molecular findings. Histopathology 53(1), 1-19.

Du, Q., Zhang, X., Cardinal, J., Cao, Z., Guo, Z., Shao, L., and Geller, D. A. (2009). Wnt/beta-catenin signaling regulates cytokine-induced human inducible nitric oxide synthase expression by inhibiting nuclear factor-kappaB activation in cancer cells. Cancer Res. 69(9), 3764-3771.

El-Serag, H. B. (2011). Hepatocellular carcinoma. N. Engl. J Med. 365(12), 1118-1127.

Fabregat, I. (2009). Dysregulation of apoptosis in hepatocellular carcinoma cells. World J Gastroenterol. 15(5), 513-520.

Hanahan, D., and Weinberg, R. A. (2011). Hallmarks of cancer: the next generation. Cell 144(5), 646-674.

Karamitopoulou, E., Cioccari, L., Jakob, S., Vallan, C., Schaffner, T., Zimmermann, A., and Brunner, T. (2007). Active caspase 3 and DNA fragmentation as markers for apoptotic cell death in primary and metastatic liver tumours. Pathology 39(6), 558-564.

Khan, M. S., Devaraj, H., and Devaraj, N. (2011). Chrysin abrogates early hepatocarcinogenesis and induces apoptosis in N-nitrosodiethylamine-induced preneoplastic nodules in rats. Toxicol. Appl. Pharmacol. 251(1), 85-94.

Lee, J., and Lim, K. T. (2012). Preventive effect of phytoglycoprotein (38 kDa) on expression of alpha-fetoprotein and matrix metalloproteinase-9 in diethylnitrosamine-treated ICR mice. Drug Chem. Toxicol. 35(3), 277-284.

Liao, X., Che, X., Zhao, W., Zhang, D., Bi, T., and Wang, G. (2010). The betaadrenoceptor antagonist, propranolol, induces human gastric cancer cell apoptosis and cell cycle arrest via inhibiting nuclear factor kappaB signaling. Oncol. Rep. 24(6), 1669-1676.

Luqman, S., and Pezzuto, J. M. (2010). NFkappaB: a promising target for natural products in cancer chemoprevention. Phytother. Res. 24(7), 949-963.

Miranda, K. M., Espey, M. G., and Wink, D. A. (2001). A rapid, simple spectrophotometric method for simultaneous detection of nitrate and nitrite. Nitric. Oxide. 5(1), 62-71.

Mocellin, S., Rossi, C. R., Pilati, P., and Nitti, D. (2005). Tumor necrosis factor, cancer and anticancer therapy. Cytokine Growth Factor Rev. 16(1), 35-53. 
Momin, R. A., and Nair, M. G. (2002). Antioxidant, cyclooxygenase and topoisomerase inhibitory compounds from Apium graveolens Linn. seeds. Phytomedicine. 9(4), 312-318.

Morris, S. M., Jr., and Billiar, T. R. (1994). New insights into the regulation of inducible nitric oxide synthesis. Am. J Physiol 266(6 Pt 1), E829-E839.

Morrison, W. B. (2012). Inflammation and cancer: a comparative view. J Vet. Intern. Med. 26(1), 18-31.

Noriyuki, M., Sumi, T., Zhi, X., Misugi, F., Nobeyama, H., Yoshida, H., Matsumoto, Y., Yasui, T., Honda, K., and Ishiko, O. (2007). Vascular endothelial growth factor, matrix metalloproteinases, and cyclooxygenase-2 influence prognosis of uterine cervical cancer in young women. Int. J Oncol. 31(3), 531-536.

Oyama, K., Shiota, G., Ito, H., Murawaki, Y., and Kawasaki, H. (2002). Reduction of hepatocarcinogenesis by ursodeoxycholic acid in rats. Carcinogenesis 23(5), 885-892.

Plati, J., Bucur, O., and Khosravi-Far, R. (2011). Apoptotic cell signaling in cancer progression and therapy. Integr. Biol. (Camb. ) 3(4), 279-296.

Powanda, M. C., Whitehouse, M. W., and Rainsford, K. D. (2015). Celery Seed and Related Extracts with Antiarthritic, Antiulcer, and Antimicrobial Activities. Prog. Drug Res. 70, 133-153.

Qin, L. X., and Tang, Z. Y. (2002). The prognostic molecular markers in hepatocellular carcinoma. World J Gastroenterol. 8(3), 385-392.

Ren, S., and Lien, E. J. (1997). Natural products and their derivatives as cancer chemopreventive agents. Prog. Drug Res. 48, 147-171.

Schattenberg, J. M., Schuchmann, M., and Galle, P. R. (2011). Cell death and hepatocarcinogenesis: Dysregulation of apoptosis signaling pathways. $J$ Gastroenterol. Hepatol. 26 Suppl 1, 213-219.

Shukla, R., Yue, J., Siouda, M., Gheit, T., Hantz, O., Merle, P., Zoulim, F., Krutovskikh, V., Tommasino, M., and Sylla, B. S. (2011). Proinflammatory cytokine TNF-alpha increases the stability of hepatitis B virus $\mathrm{X}$ protein through NF-kappaB signaling. Carcinogenesis 32(7), 978-985.

Sivaramakrishnan, V., and Niranjali, D. S. (2009). Morin regulates the expression of NF-kappaB-p65, COX-2 and matrix metalloproteinases in diethylnitrosamine induced rat hepatocellular carcinoma. Chem. Biol. Interact. 180(3), 353-359.

Song, Y., Jin, S. J., Cui, L. H., Ji, X. J., and Yang, F. G. (2013). Immunomodulatory effect of Stichopus japonicus acid mucopolysaccharide on experimental hepatocellular carcinoma in rats. Molecules. 18(6), 7179-7193.

Stoimenov, I., and Helleday, T. (2009). PCNA on the crossroad of cancer. Biochem. Soc. Trans. 37(Pt 3), 605-613.

Strzalka, W., and Ziemienowicz, A. (2011). Proliferating cell nuclear antigen (PCNA): a key factor in DNA replication and cell cycle regulation. Ann. Bot. 107(7), 1127-1140. 
Sultana, S., Ahmed, S., Jahangir, T., and Sharma, S. (2005). Inhibitory effect of celery seeds extract on chemically induced hepatocarcinogenesis: modulation of cell proliferation, metabolism and altered hepatic foci development. Cancer Lett. 221(1), 11-20.

Tan, A. C., Konczak, I., Sze, D. M., and Ramzan, I. (2011). Molecular pathways for cancer chemoprevention by dietary phytochemicals. Nutr. Cancer 63(4), 495505.

Ueno, S., Aoki, D., Kubo, F., Hiwatashi, K., Matsushita, K., Oyama, T., Maruyama, I., and Aikou, T. (2005). Roxithromycin inhibits constitutive activation of nuclear factor \{kappa B by diminishing oxidative stress in a rat model of hepatocellular carcinoma. Clin. Cancer Res. 11(15), 5645-5650.

Wallace, M. C., Preen, D., Jeffrey, G. P., and Adams, L. A. (2015). The evolving epidemiology of hepatocellular carcinoma: a global perspective. Expert. Rev. Gastroenterol. Hepatol. 9(6), 765-779.

Yokoo, H., Yasuda, J., Nakanishi, K., Chuma, M., Kamiyama, T., Todo, S., Hirohashi, S., and Sakamoto, M. (2011). Clinicopathological significance of nuclear factor-kappaB activation in hepatocellular carcinoma. Hepatol. Res. 41(3), 240-249.

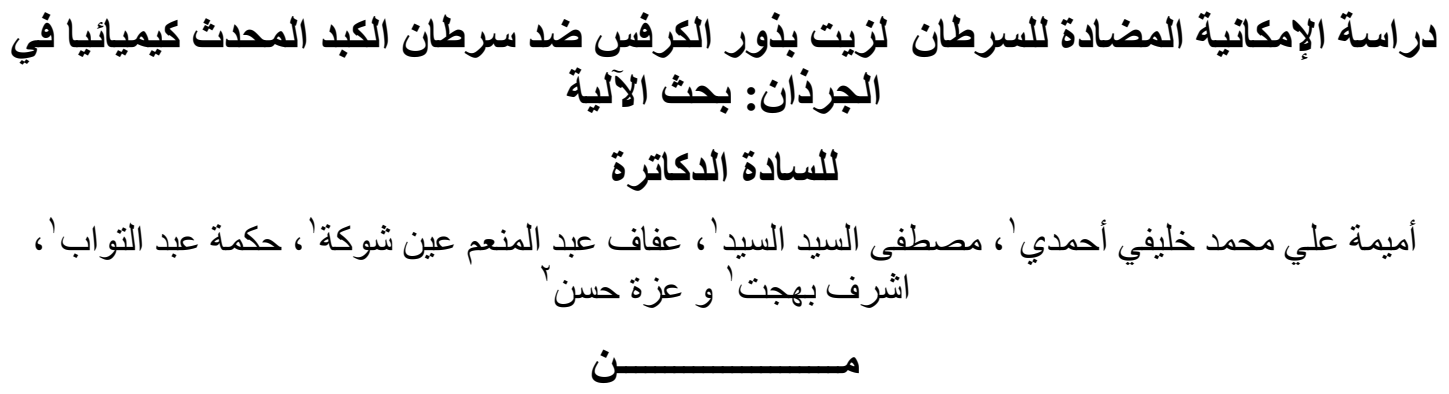

سرطان الخلايا الكبدية، يمنل ورما خبيثا معقدا وقاتلا تكون في المقام الأول بسبب الاكسدة و إحداث

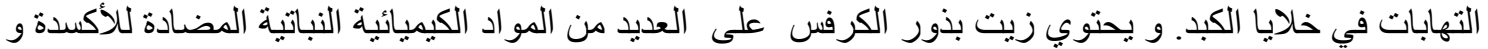

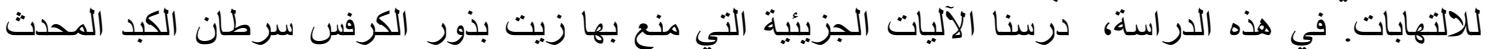

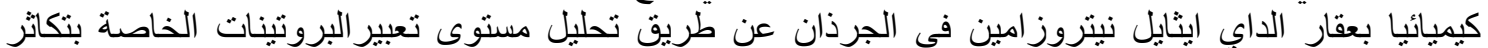

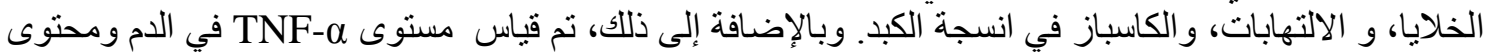

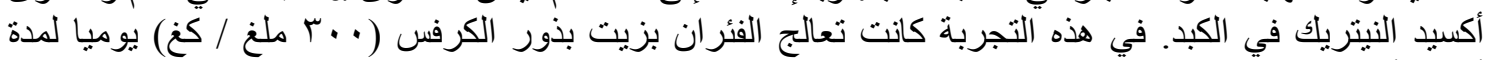

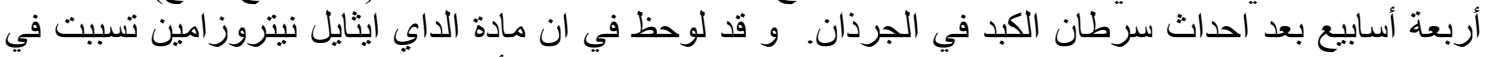

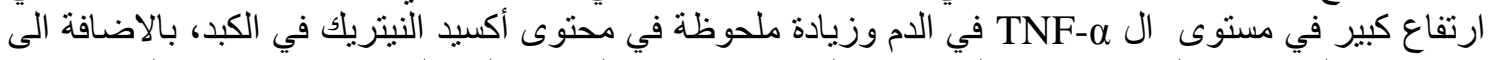

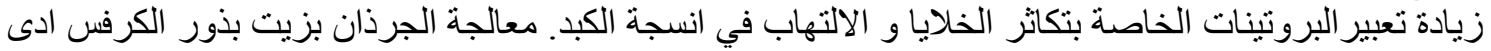

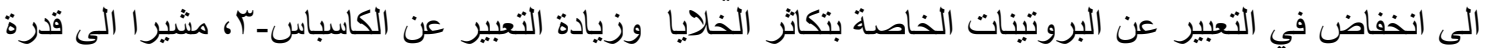

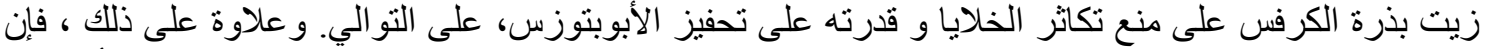

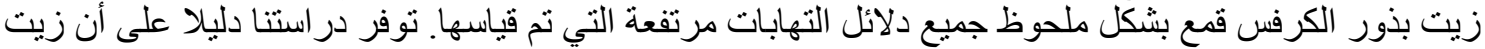

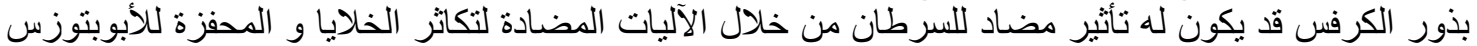

